\title{
APLICAÇÃO DO SISTEMA HAZARD ANALYSIS AND CRITICAL CONTROL POINTS (HACCP) NO PROCESSAMENTO DE CARNE BOVINA FRESCA
}

\author{
JOÃO TOMAZ DA SILVA BORGES * \\ ARLAN SILVA FREITAS **
}

\begin{abstract}
Apresenta breve discussão sobre proposta de implementação do sistema HACCP em unidades de processamento de carne bovina fresca. Tratandose de produto altamente perecível e apresentando condições favoráveis ao desenvolvimento microbiano, a carne bovina é freqüentemente considerada como veículo de doenças transmitidas por alimentos. Conclui que a utilização adequada de medidas higiênicas e de conservação é importante na garantia da qualidade microbiológica, química e física das diferentes etapas de obtenção da carne bovina fresca.
\end{abstract}

PALAVRAS-CHAVE: PONTOS CRÍTICOS DE CONTROLE-PROCESSAMENTO; CARNE BOVINA-PROCESSAMENTO; HACCP.

\section{INTRODUÇÃO}

Os produtos crus de origem animal são comercializados no estado nãoprocessado (fresco ou resfriado) e sua qualidade e segurança microbiológica dependem do controle desenvolvido durante a produção, preparação e armazenamento.

Os sistemas de produção e inspeção de produtos alimentícios estão sendo substituídos gradualmente por sistemas de asseguramento da qualidade, nos quais problemas considerados críticos são prevenidos antes que ocorram (OGAWA e MAIA, 1999).

* Economista Doméstico, Especialista em Administração de Serviços de Alimentação, Mestre em Ciência e Tecnologia de Alimentos, Universidade Federal Rural do Rio de Janeiro (UFRRJ), RJ. (e-mail: jtsborges@hotmail.com.br).

** Químico Industrial, Mestre em Ciência e Tecnologia de Alimentos, UFRRJ, RJ. (e-mail: arlanfreitas@yahoo.com.br). 
Os produtos alimentícios de origem animal, em especial a carne bovina, são facilmente contaminados antes, durante e após o abate. As contaminações provocadas durante o processamento promovem alterações no valor nutricional e nas características sensoriais (cor, odor, sabor e textura). Além disso, etapas como sangria, esfolamento, evisceração, corte e desossa favorecem a colonização dos tecidos por microrganismos deteriorantes e patogênicos (SENAI, 1999; FRANCO e LANDGRAF, 1996). Assim, um dos objetivos da tecnologia de alimentos é conseguir estender a vida de prateleira destes produtos. Contudo, dois problemas básicos dificultam a extensão da vida de prateleira dos produtos cárneos. Primeiro, os tecidos animais sofrem constantes reações bioquímicas (enzimáticas) e segundo, o desenvolvimento de microrganismos precisa ser retardado. O controle destes dois parâmetros é crítico na produção de carne bovina. Com a aplicação do sistema Hazard Analysis and Critical Control Points (HACCP) é possível atingir condições ideais de processamento e conservação (CORDOBA, CORDOBA, LOPEZ e JORDANO, 1998).

O presente trabalho teve por objetivo listar os principais pontos críticos de controle (PCC) no processo de obtenção da carne bovina e apresentar medidas de controle e monitoramento.

\section{O SISTEMA HAZARD ANALYSIS AND CRITICAL CONTROL POINTS (HACCP)}

O sistema HACCP é reconhecido internacionalmente como o melhor método de garantia de segurança de produtos alimentícios, que permite identificar riscos específicos e medidas preventivas para seu controle (KVENBERG et al., 2000).

O sistema HACCP de segurança alimentar foi criado em 1959, pela Pillsbury Company, Army Natick Research and Development Laboratories e a National Aeronautics and Space Administration (NASA), nos Estados Unidos da América (EUA), para produção de alimentos a serem consumidos no espaço, com garantia da ausência de microrganismos patogênicos, toxinas, produtos químicos e físicos (SBCTA, 1995).

Registros da International Commission on Microbiological Specifications for Foods (ICMSF) reconhecem a importância internacional do sistema HACCP e sua utilidade na garantia da segurança alimentar (SIMONSEN et al., 1987). 
O conceito do HACCP foi apresentado ao público em 1971, pela Pillsbury Company, na Conferência Nacional sobre Proteção de Alimentos, que posteriormente serviu de base para o treinamento dos inspetores do Food and Drugs Administration (FDA). Foi observado que o sistema poderia ser empregado em indústrias processadoras de alimentos enlatados de baixa acidez e depois em indústrias processadoras de carne (ALMEIDA, 1998).

Avaliando a eficiência das normas alimentícias, o subcomitê de Academia Nacional de Ciência dos EUA recomendou, em 1985, a divulgação do HACCP para que fosse adotado por estas agências reguladoras. Esta recomendação conduziu a formação, em 1987, do National Advisory Committee on Microbiological Criteria for Foods (NACMCF). O Comitê expandiu o protocolo do HACCP de três princípios para sete, ou seja, análise dos perigos e medidas preventivas de controle, identificação dos pontos críticos de controle (PCC), estabelecimento dos limites críticos para as medidas preventivas monitoradas em cada PCC, estabelecimento dos procedimentos de monitorização dos PCC, estabelecimento das ações corretivas para casos de desvios dos limites críticos, estabelecimento dos procedimentos de verificação e estabelecimento dos procedimentos de registro (ALMEIDA, 1998; SBCTA, 1995).

\section{MICROBIOLOGIA DA CARNE: ALTERAÇÕES DE ORIGEM MICROBIANA}

A carne é o meio de cultura ideal para o desenvolvimento microbiano por apresentar alta atividade de água $\left(\mathrm{a}_{\mathrm{w}}\right)$ e ser rica em substâncias nitrogenadas, minerais e fatores de crescimento. Além disso, seu pH é favorável $(5,6)$ à maioria dos microrganismos, cujo desenvolvimento dependerá, sobretudo, das condições de abate, estresse do animal e higiene durante a manipulação. Os tipos mais comuns de deterioração de carnes podem ser classificados de acordo com o ambiente que envolve estes produtos e são provocados por bactérias, bolores ou leveduras. Em condições de aerobiose, as bactérias produzem modificações na cor, sabor, aroma e gordura presente na carne (PIERSON e CORLETT JR., 1992).

A temperatura e a umidade da superfície da carne e do ar podem favorecer o crescimento de microrganismos causadores da mucosidade ou limo superficial (Tabela 1). A alteração pode ter como responsáveis espécies do gênero Pseudomonas, Achromobacter, Leuconostoc, Streptococcus, 
Micrococcus, Bacillus e alguns Lactobacillus (FRANCO e LANDGRAF, 1996).

\section{TABELA 1 - NÚMERO DE MICRORGANISMOS NO MOMENTO DO APARECIMENTO DE ODOR E LIMOSIDADE EM ALIMENTOS PROTÉICOS}

\begin{tabular}{l|c|c}
\hline \multirow{2}{*}{\multicolumn{1}{c}{ Alimento }} & \multicolumn{2}{c}{ Número } \\
\cline { 2 - 3 } & Odor evidente & Limosidade evidente \\
\hline Carne de frango & $2,5-100 \times 10^{6} / \mathrm{cm}^{2}$ & $10-60 \times 10^{6} / \mathrm{cm}^{2}$ \\
Carne de vaca & $1,2-100 \times 10^{6} / \mathrm{cm}^{2}$ & $3-300 \times 10^{6} / \mathrm{cm}^{2}$ \\
Salsichas & $1,0-1,3 \times 10^{8} / \mathrm{cm}^{2}$ & $1,3 \times 10^{8} / \mathrm{cm}^{2}$ \\
Peixe & $1,0-130 \times 10^{6} / \mathrm{cm}^{2}$ & - \\
Ovos ou ovos líquidos & $10 \times 10^{6} / \mathrm{g}$ & - \\
\hline
\end{tabular}

Fonte: FRAZIER e WESTHOFF, 1993.

Os pigmentos hemoglobina e mioglobina da carne são indicadores de qualidade, pois o músculo não dispõe de sangue fresco para transportar substrato para síntese de energia e manutenção de suas funções normais. A exposição da carne às mais variadas condições (calor, acidez e agentes químicos) favorece a oxidação do ferro presente nestes pigmentos, alterando sua cor. Estes pigmentos, além de indicadores de frescor (tornamse pardos com o tempo) são também indicadores de alterações físicas, químicas ou bacterianas (PRICE e SCHWEIGERT, 1994).

A cor vermelha da carne pode adquirir tons de verde, marrom ou cinza decorrentes da ação dos oxidantes, gás sulfídrico $\left(\mathrm{H}_{2} \mathrm{~S}\right)$ e peróxidos $\left(\mathrm{H}_{2} \mathrm{O}_{2}\right)$, produzidos por bactérias. O primeiro ocorre pela exposição ao ar de carnes e derivados embalados a vácuo, ou devido ao crescimento de microrganismos no centro da peça. O segundo ocorre geralmente em carnes vermelhas frescas embaladas a vácuo ou impermeáveis a trocas gasosas e conservadas em temperaturas entre 1 e $5^{\circ} \mathrm{C}$ (FRANCO e LANDGRAF, 1996). 
A coloração normal da carne pode sofrer alterações devido à ação de leveduras produtoras de pigmentos (branco, marrom, rosa ou creme) e bolores como Sporotricum carnis (pontos brancos) e Penicillium (pontos verdes). Algumas espécies de mofos desenvolvem-se em carnes a temperatura de $-5^{\circ} \mathrm{C}$ (HAYES, 1993).

As principais alterações da carne, provocadas por mofos, são a pegajosidade na superfície do produto e o desenvolvimento micelar (whiskers), causadas por espécies dos gêneros Mucor (M. racebiosus, M. Iusitanicus), Tamnidium (T. chaeto cladioides, T. elegans) e Rhizopus (FRAZIER e WESTHOFF, 1993). O acondicionamento sob temperaturas próximas ao congelamento pode favorecer a formação de micélio cotonoso, sem esporulação, de coloração branca (FRANCO e LANDGRAF, 1996).

Putrefação significa decomposição anaeróbia de proteínas com produção de compostos de aroma desagradável como $\mathrm{H}_{2} \mathrm{~S}$, indol, escatol, putrescina, cadaverina e outros. O Clostridium é o causador mais comum desse tipo de deterioração, embora bactérias aeróbias facultativas também possam estar envolvidas. De modo geral, a deterioração de produtos cárneos depende tanto de sua composição como da temperatura em que o produto é mantido (JAY, 1994).

A acidificação ocorre principalmente devido ao acúmulo de ácidos orgânicos (fórmico, acético, propiônico) durante a degradação enzimática bacteriana de moléculas complexas. Proteólise sem putrefação, causada por bactérias anaeróbias-facultativas (Clostridium butíricos e Coliformes), pode contribuir também para a acidificação. Bactérias lácticas estão presentes em quase todo tipo de produto cárneo fresco ou curado, crescendo também em temperaturas de refrigeração. Esse desenvolvimento é desejável (fermentação láctica) na superfície ou interior da peça, porém a produção de ácido láctico e outros ácidos em excesso pode originar coloração esverdeada no produto (FRAZIER e WESTHOFF, 1993).

\section{PROCESSAMENTO DE OBTENÇÃO DE CARNE FRESCA}

As etapas de processamento de carne bovina crua e os pontos críticos de controle são apresentados na Figura 1. A cada etapa observada, a qualidade e segurança do produto estão sujeitas à contaminação pelo uso inadequado das boas práticas higiênicas (CODEX ALIMENTARIUS, 1994). 


\section{FIGURA 1 - FLUXOGRAMA PARA PRODUÇÃO E PROCESSAMENTO DE CARNE BOVINA FRESCA}

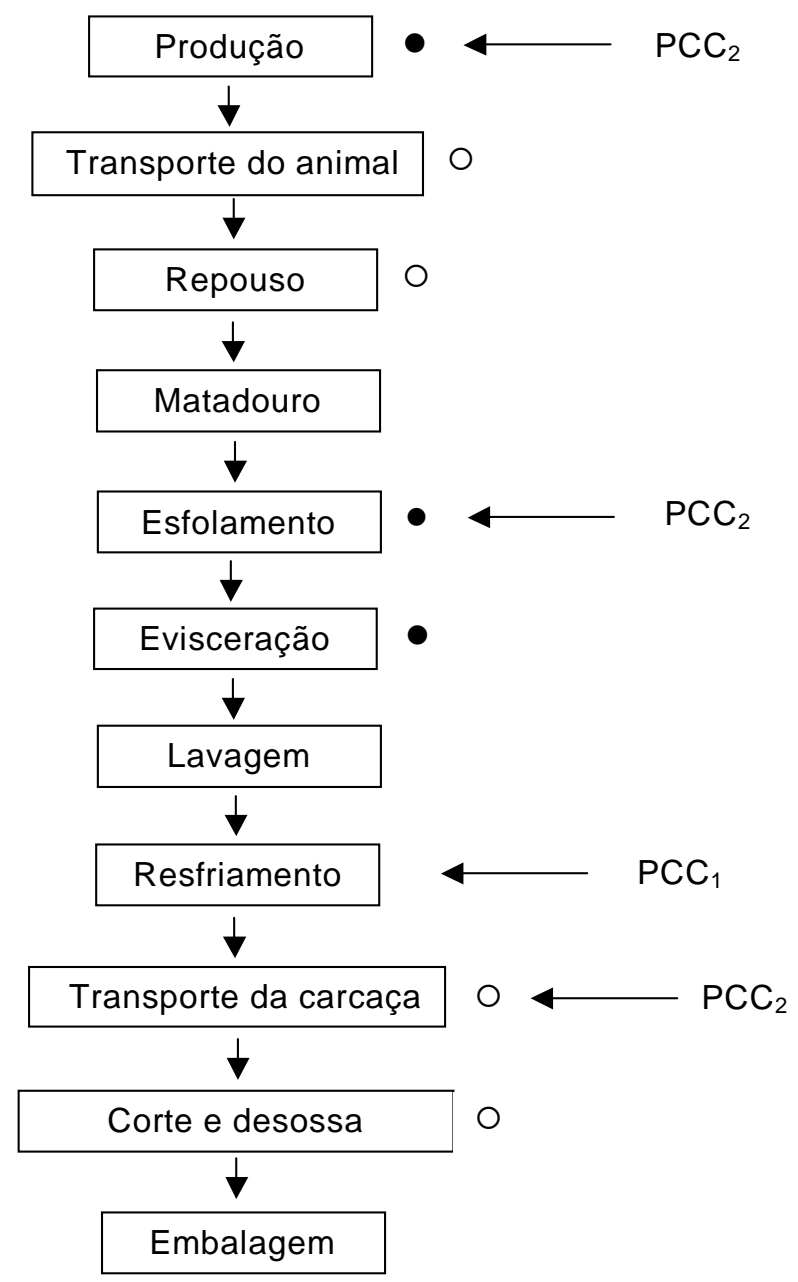

Indica situação de menor contaminação;

- Indica situação de maior contaminação; 
$\mathrm{PCC}_{1}$, eficiente; $\mathrm{PCC}_{2}$ não absoluto.

Fonte: ICMSF, 1997.

\section{DESCRIÇÃO DAS ETAPAS E APLICAÇÃO DO SISTEMA HACCP}

\subsection{PRODUÇÃO}

A contaminação da carne bovina pode ocorrer por via endógena (quando o animal está vivo) ou exógena, desde o abate do animal até o consumo de seus produtos. Entretanto, sua principal via de contaminação ocorre no meio externo, por exposição direta e freqüente às diferentes e inúmeras fontes orgânicas de contaminação. A prática dos princípios básicos de higiene é fator essencial na obtenção de carnes e produtos cárneos com menor índice possível de contaminação, melhor qualidade sensorial e nutricional (EVANGELISTA, 2000).

Sem a utilização de práticas adequadas de produção, na fazenda, muitos agentes de doenças transmissíveis ao homem (Salmonella, Trichinella, Clostridium, Campylobacter, Yersínia, etc.) deixam de ser controlados, bem como os agentes físicos (pêlos, partículas de areia entre outros) e químicos (hormônios, antibióticos, pesticidas e outros) (ICMSF, 1997).

A industrialização e o desenvolvimento de práticas agrícolas intensivas tem desenvolvido a possibilidade do aparecimento de resíduos perigosos na carne como antibióticos, anti-helmínticos, hormônios, substâncias parecidas com hormônios, pesticidas, tranqüilizantes e metais tóxicos. Alguns componentes da alimentação animal ou contaminantes do pasto, como também agentes terapêuticos ou de promoção de crescimento, podem permanecer nos tecidos após o abate constituindo perigo para 0 consumidor (NACMCF, 1993).

A qualidade e a segurança microbiológica de produtos crus dependem do controle desenvolvido durante a produção, preparação, armazenamento e apresentação para comercialização. Produtos de origem animal estão sujeitos à contaminação microbiana a partir de várias fontes, sendo que o próprio animal contribui com organismos patógenos ou deteriorantes. Outras fontes de contaminação podem ocorrer por meio da água, instalações, equipamentos e manipuladores. É necessário conhecimento das prováveis fontes de contaminação e dos diferentes meios de difusão para que seu controle seja maximizado e os microrganismos patógenos sejam excluídos sempre que possível (RIEDEL, 1992; FRANCO e LANDGRAF, 1996). 


\subsubsection{Controle e monitoramento}

- O uso das boas práticas agrícolas é o principal meio de controlar as doenças nos animais da fazenda.

- Animais originários de outros lugares, alimentos e/ou água contaminados e práticas inadequadas de eliminação de dejetos são fontes de enfermidades que propiciam a proliferação de doenças causadas por microrganismos.

- Deve-se garantir o uso das boas práticas agrícolas e assistência veterinária aos animais, bem como a qualidade da alimentação, água e eliminação de dejetos.

- É necessário registrar casos de doenças e controlar a entrada de animais na fazenda, mediante inspeção sanitária.

\subsection{TRANSPORTE DO ANIMAL}

Os transportes difíceis e penosos, em circunstâncias especiais, podem ocasionar stress do animal, e assim, substâncias metabólicas que se formam, podem atravessar a barreira intestinal, prejudicando as condições normais da carne. Por idêntico mecanismo, microrganismos saprófitas e patogênicos presentes no intestino ultrapassam as paredes do mesentério e atingem o sangue e os músculos. A fadiga causada ao animal pelas condições inadequadas de transporte, quando enviado diretamente ao corte, produz ainda alterações no ciclo do glicogênio e conseqüente formação de ácido láctico, que interfere no processo de maturação da carne (EVANGELISTA, 2000; RIEDEL, 1992).

\subsubsection{Controle e monitoramento}

- Selecionar os animais sadios, limpos e com intestino vazio, pois será mais fácil evitar a difusão da contaminação fecal.

- Deixar os animais sem alimentação pelo período de 3 a 6 horas antes do transporte.

- Evitar situações de stress e ferimento do animal durante o carregamento, transporte e descarregamento. 


\subsection{REPOUSO}

O manejo adequado de animais destinados ao abate contribui para a redução da contaminação bacteriana da carcaça (EUSTACE, 1981).

A condição e manutenção da qualidade da carcaça dependem da atenção dada ao animal antes do abate, o que constitui parte essencial da operação. O repouso é importante para garantir o retorno às funções metabólicas normais, pelo controle de situações de stress, reduzindo riscos de contaminação da carcaça e protegendo animais e manipuladores em casos de doenças contagiosas (ICMSF, 1997).

O animal antes do abate deve ser submetido à inspeção sanitária para verificar se o estado de saúde deste permite o abate e posterior consumo humano. Nessa inspeção serão rejeitados animais em gestação, extremamente magros e com enfermidades patogênicas, ferimentos externos, miíases e outros focos purulentos (ICMSF, 1997).

Os animais, antes do abate, devem passar por sistemas de chuveiros, com água hiperclorada (15 ppm). Este banho tem como finalidade limpar os animais pela remoção de detritos e promover a vasoconstrição periférica, permitindo maior sangria.

\subsubsection{Controle e monitoramento}

- Garantir o repouso do animal.

- Certificar-se do seu estado de saúde e das condições higiênicas antes do abate.

- Dosar a concentração de cloro na água utilizada para higienização do gado.

\subsection{MATADOURO}

Os métodos usualmente empregados no abate de animais podem favorecer a inoculação de microrganismos nos tecidos, porém, mediante aplicação de normas higiênicas (limpeza e sanitização de facas de abate entre um animal e outro), a quantidade de microrganismos inoculados não é suficiente para constituir perigo (ICMSF, 1997). 
Bactérias patogênicas como Salmonella sp, Escherichia coli, Staphylococcus aureus, Yersínia enterocolitica e Clostridium perfringens podem ser encontradas na carne, sendo esta também responsável por fontes esporádicas de casos de Escherichia coli O157:H7. Estes microrganismos geralmente contaminam a carne mediante condições inadequadas de abate, manipulação e armazenamento. $O$ emprego do plano HACCP contribui para o controle destes patógenos assim como de outros (SENAI, 1999; NACMCF, 1993).

Abate e manipulação em condições de limpeza, refrigeração e armazenamento adequados, freqüente limpeza e desinfecção das câmaras e utensílios, redução do movimento de pessoal, práticas adequadas de higiene corporal, tratamento e fornecimento de água contribuem para diminuir o índice de contaminação durante o abate e processamento da carne (RIEDEL, 1992).

As possibilidades de contaminação da carne durante o abate poderão ocorrer no ato da introdução do instrumento perfurante no corpo do animal e produção da sangria, operação importante por seu aspecto higiênicosanitário e comercial, que deve ocorrer imediatamente após o processo de insensibilização. A sangria deverá ser executada em animais suspensos por dispositivos aéreos de modo a evitar contato com microrganismos do solo (EUSTACE, 1981). O sangue deve ser removido completamente o mais rápido possível, pois se trata de excelente meio de cultura oferecendo condições favoráveis ao crescimento e multiplicação de microrganismos (principalmente os responsáveis por processos deteriorativos) e sua distribuição pela carcaça. O estado de repouso do animal é também considerado fator importante para o êxito da sangria.

A sangria aumenta a capacidade de trabalho do coração e torna mais intensa a circulação, resultando em fibrilação ventricular e parada cardíaca. Com isso, microrganismos presentes na região do local da sangria e no tubo digestivo do animal são transportados por todo o corpo. É também possível que durante a agonia ocorra contaminação da carne, devido a maior saída de líquido das membranas e capilares que ficam com a permeabilidade aumentada, favorecendo a passagem dos microrganismos para os tecidos. Os principais microrganismos intestinais que podem atingir os músculos através do sangue são Clostridium perfringens, Salmonella sp, Streptococcus bovi, Enterococcus faecum e S. durans (EVANGELISTA, 2000). 


\subsubsection{Controle e monitoramento}

- Disponibilizar detergente neutro, soluções de álcool $70 \%$, iodo $0,1 \%$ e cloro 200 ppm.

- Certificar-se do uso e concentrações destes produtos na higienização de ambientes, equipamentos, utensílios e manipuladores.

- Garantir, no intervalo de abate dos animais, a sanitização do instrumento utilizado para a operação.

- Controlar a sangria, evitando a multiplicação e distribuição microbiana na carcaça.

\subsection{ESFOLAMENTO}

A utilização de medidas básicas de higiene é importante na prevenção da contaminação da carne. No decorrer do esfolamento, o uso inadequado de medidas higiênicas pode gerar contaminações da carne pela existência de inúmeras espécies microbianas na pele dos animais. O esfolamento é realizado por meio de instrumentos cortantes, por sistemas elétricos ou pneumáticos, sendo obedecidas as etapas de primeira culatra, cabeceiro, segunda culatra e costela (EVANGELISTA, 2000).

Após a sangria são efetuadas várias operações com a finalidade de garantir condições suficientes para que as carnes sejam consumidas, armazenadas ou industrializadas. Algumas operações favorecem a contaminação da carcaça mais lentamente do que outras. Durante a retirada do couro pode ocorrer contaminação quando o manipulador e a faca entram em contato com o couro, o pêlo e a carne.

\subsubsection{Controle e monitoramento}

- Disponibilizar detergente neutro, soluções de álcool 70\%, iodo 0,1\% e cloro 200 ppm.

- Certificar-se do uso e concentrações destes produtos na higienização de ambientes, equipamentos, utensílios e manipuladores.

\subsection{EVISCERAÇÃO}

O trato intestinal é a segunda maior fonte de patógenos entéricos durante 
o processo de abate (NACMCF, 1993).

É essencial que as vísceras não sejam cortadas, pois podem contaminar o manipulador, a carcaça, utensílios e equipamentos usados. A utilização adequada de higiene é importante na prevenção de contaminações (NACMCF, 1993; EUSTACE, 1981; CODEX ALIMENTARIUS, 1994).

O tempo de evisceramento deve ser no máximo de 20 a 30 minutos, pois quanto mais tempo transcorre, maiores são as possibilidades de penetração de microrganismos intestinais nos tecidos (EVANGELISTA, 2000).

Paredes, piso, água, ar, utensílios, equipamentos e manipuladores podem oferecer riscos de contaminação à matéria-prima (ANDRADE e MACÊDO, 1996).

\subsubsection{Controle e monitoramento}

- Não cortar as vísceras durante o evisceramento certificando-se do tempo de duração da operação.

- Disponibilizar detergente neutro, soluções de álcool $70 \%$, iodo $0,1 \%$ e cloro 200 ppm.

- Certificar-se do uso e das concentrações destes produtos na higienização de ambientes, equipamentos, utensílios e dos manipuladores.

\subsection{LAVAGEM}

A etapa da lavagem pode disseminar a contaminação presente e contribuir para a formação de aerossóis, sendo comum o uso de substâncias bactericidas. A lavagem excessiva das carcaças pode resultar em excesso de umidade, dificultando a desidratação superficial durante a estocagem e aumentando os riscos de deterioração por parte da microbiota remanescente (SENAI, 1999).

A lavagem a jato pode ser razoavelmente eficiente na remoção de alguma contaminação visível, mas pêlos e máculas que surgem do contato com fezes ou conteúdo dos intestinos, provavelmente permanecerão. A lavagem a jato é parcialmente eficiente na remoção da contaminação microbiana. Lavagem excessiva e uso de jatos a alta pressão podem afetar prejudicialmente a carcaça, destruindo a integridade da membrana 
superficial e inflando a gordura da superfície. Até que não estejam disponíveis técnicas comerciais eficientes a lavagem não pode ser considerada como PCC (ICMSF, 1997).

\subsection{RESFRIAMENTO}

$\mathrm{Na}$ refrigeração utilizam-se temperaturas superiores às do ponto de congelamento. É empregada como meio de conservação básica (como no caso de carnes e pescados frescos) ou conservação temporária até que se aplique outro método (SENAI, 1999).

Ao completar a preparação, a superfície quente $\left(30-40{ }^{\circ} \mathrm{C}\right)$ e úmida da carcaça é ideal para a multiplicação de patógenos e deteriorantes. Esta superfície deve ser resfriada $\left(7^{\circ} \mathrm{C}\right.$ ou menos), reduzindo a multiplicação microbiana (ICMSF, 1997). Nesta etapa não ocorre eliminação de microrganismos, havendo apenas a inibição (mesófilos e termófilos) ou diminuição (psicrotróficos) do seu crescimento (HAYES, 1993; JAY, 1994).

A circulação do ar é necessária para que haja distribuição uniforme da temperatura dentro da câmara. Este ponto é muito importante, pois se a circulação for fraca a diminuição da temperatura no interior do alimento pode ser lenta, aumentando o risco do crescimento de patógenos. Para efetiva transferência do calor, fluxo de ar de pelo menos $0,25 \mathrm{~m} / \mathrm{s}$ deveria ser mantido sobre todas as partes da carcaça (ICMSF, 1997; SENAI, 1999).

O resfriamento rápido da carne antes do rigor-mortis pode resultar em dureza induzida pelo frio. Os efeitos do encolhimento causado pelo frio podem ser evitados mediante estimulação elétrica logo após o abate. Ao estabelecer a operação de abate é necessário compensar os benefícios do resfriamento rápido e da secagem superficial contra a perda de peso e dessecamento da superfície, que pode prejudicar a aparência do produto (ICMSF, 1997).

\subsubsection{Controle e monitoramento}

- Certificar-se que não ocorra condensação nos resfriadores pelos efeitos combinados de temperatura, fluxo de ar e umidade relativa, evitando desta forma, multiplicação microbiana durante o resfriamento.

- Providenciar medidas corretivas caso ocorra desvio nos limites pré- 
determinados.

- Medir e registrar a temperatura e umidade periodicamente, verificando visualmente a eficiência da limpeza rotineira do frigorífico.

\subsection{TRANSPORTE DA CARCAÇA}

Transporte inadequado e danos sofridos (golpes, atritos ou esmagamento) influenciam a qualidade da carne, tornando-a imprópria para o consumo, além de favorecer o desenvolvimento de microrganismos nocivos. Nos estabelecimentos de abate, entre as várias dependências, as carnes são conduzidas através de recipientes, bandejas, carrinhos e outros, podendose prever numerosas possibilidades de contaminação. Quando enviados para os centros em que serão vendidas, industrializadas, conservadas e armazenadas, as carnes acondicionadas ou não, são transportadas em diversos veículos, alguns deles dotados de sistemas refrigerantes (EVANGELISTA, 2000).

O transporte irregular transforma-se em potente fator de contaminação, agravado por condições inadequadas de refrigeração, seccionamento, descongelamento, condições técnicas e higiênicas, embalagem e armazenamento. O sistema de transporte e os recipientes devem ser de material liso, resistente, impermeável, atóxico, de fácil higienização, permitindo separação efetiva de produtos alimentícios diferentes e proteção contra contaminações, oscilações de temperatura, umidade, atmosfera e demais condições que favoreçam o desenvolvimento microbiano (BARUFFALDI e OLIVEIRA, 1998; ABERC, 1998; ICMSF, 1997).

Carnes e produtos cárneos, alimentos congelados ou super congelados, produtos que necessitam de temperatura especial de conservação e refeições prontas para consumo devem ser transportadas em local fechado, isotérmico ou refrigerado. Deste modo, as temperaturas para transporte destes alimentos são de 4 a $6{ }^{\circ} \mathrm{C}$ para os refrigerados, de 6 a $10^{\circ} \mathrm{C}$ quando resfriados e $-18 \mathrm{a}-15^{\circ} \mathrm{C}$ se congelados (SILVA JR., 1995).

\subsubsection{Controle e monitoramento}

- Certificar-se das condições de transporte (higiene, temperatura e tempo) e condições de higiene do ambiente, recipientes, utensílios e equipamentos utilizados no preparo da carne.

- Disponibilizar detergente neutro, soluções de álcool 70\%, iodo 0,1\% e 
cloro 200 ppm.

- Certificar-se do uso e concentrações destes produtos na higienização de ambientes, equipamentos, utensílios e manipuladores.

\subsection{CORTE E DESOSSA}

Superfícies e equipamentos inadequadamente limpos, usados no corte e desossa, podem representar fonte de microrganismos deteriorantes psicrotróficos. O processo favorece a disseminação e multiplicação microbiana. Isto é crucial para a vida de prateleira da carne. Projeto, manutenção e higiene da instalação, utensílios e equipamentos são importantes. A temperatura da sala de corte deve ser mantida em $10^{\circ} \mathrm{C}$ ou menos. Deve ser evitado o uso de panos de esfregar, tábuas de corte em madeira e correias transportadoras absorventes (ICMSF, 1997).

Para facilitar o transporte e distribuição das carnes do abatedouro aos locais de consumo é feita a divisão dos canais, primeiro em duas partes e posteriormente em quartos. Os cortes necessários são feitos por serra elétrica e excepcionalmente por machadinhas. Após a divisão e liberação sanitária, a carne de acordo com seu destino é resfriada ou congelada imediatamente, antes ou depois de transportada.

\subsubsection{Controle e monitoramento}

- Esterilizar os instrumentos de corte e utensílios em geral a $85^{\circ} \mathrm{C}$ durante a produção.

- Realizar a sanitização em água clorada (200ppm).

- Recomenda-se para manipuladores, o uso de soluções de álcool $70 \%$ e iodo $0,1 \%$.

- Medir a temperatura ambiente.

- Certificar-se do uso de tábuas de polipropileno, mesas de aço-inoxidável isentas de cortes e/ou sulcos profundos que permitam o alojamento de microrganismos e correias transportadoras que não absorvam umidade.

\subsection{EMBALAGEM}

A embalagem protege a carne da contaminação adicional e impede a perda da umidade. Bactérias aeróbias deteriorantes, particularmente Pseudomonas spp., crescem prontamente em condições de alta umidade 
sobre carnes envoltas em filme impermeável ao oxigênio. A utilização desta forma de embalagem é limitada à carne fresca nas vitrines dos locais de venda (ICMSF, 1997).

A embalagem em filme impermeável aos gases muda o ambiente gasoso dentro do pacote afetando a taxa de desenvolvimento e a natureza da microbiota. O acúmulo de dióxido de carbono inibe os piscrotróficos Gramnegativos. A microbiota que se desenvolve compreende principalmente bactérias ácido-lácticas cuja atividade é menos nociva para a carne. Carne com alto $\mathrm{pH}$ têm vida de prateleira menor no estado resfriado e, portanto, quando for importante conservar a qualidade, o $\mathrm{pH}$ da carne destinada a ser embalada a vácuo deveria ser monitorado (ICMSF, 1997).

\section{CONCLUSÃO}

Os produtos de origem animal, em especial a carne bovina são alimentos largamente consumidos. Contudo, maior expansão neste segmento de mercado tem sido dificultada pela redução da vida útil decorrente de alterações fisiológicas, bioquímicas e microbiológicas a que estes produtos são susceptíveis durante o processamento. A carne é altamente perecível e sujeita à ação de diferentes microrganismos. A qualidade microbiológica no decorrer da cadeia produtiva da carne bovina fresca é fator importante para a segurança do produto final e conseqüentemente do consumidor. A manutenção de suas características físicas, químicas e microbiológicas é um desafio que dia-a-dia enfrentam seus produtores. Neste sentido é importante conhecer medidas de controle de qualidade que permitam maior segurança destes produtos, mantendo suas características nutricionais e sensoriais.

\section{Abstract}

APPLICATION OF THE HAZARD ANALYSIS AND CRITICAL CONTROL POINTS (HACCP) SYSTEM IN THE FRESH MEAT PROCESSING

This article presents a brief discussion upon the purpose of HACCP (Hazard Analysis and Critical Control Points) in the fresh meat processing. Due to be a product highly perishable and presenting favorable conditions to microorganisms development, the cattle meat is usually considered as vehicule of food transmitted diseases. Concludes that the improvement of processing conditions, utilization of hygienic measure and conservation is very important in the safety of microbiological, chemical and physical quality of the obtention stages of fresh meat.

KEY WORDS: CRITICAL CONTROL POINTS-PROCESSING; BOVINE MEATPROCESSING; HACCP. 


\section{REFERÊNCIAS}

1 ABERC. Associação Brasileira das Empresas de Refeições Coletivas. Manual ABERC de práticas de elaboração e serviço de refeições para coletividades. 4. ed. São Paulo, 1998. $195 \mathrm{p}$.

2 ALMEIDA, C.R. O sistema HACCP como instrumento para garantir a inocuidade dos alimentos. Higiene Alimentar, v. 12, n. 53, p. 12-20, jan./fev. 1998.

3 ANDRADE, N.J.; MACÊDO, J.A.B. Higienização na indústria de alimentos. São Paulo: Varela, 1996. 182 p.

4 BARUFFALDI, R. e OLIVEIRA, M.N. de. Fundamentos de tecnologia de alimentos. São Paulo: Atheneu, 1998. v. 3.

5 CODEX ALIMENTARIUS. Recommended international code of hygienic practice for fresh meat. Roma, 1994. v. 10, p. 83-111.

6 CORDOBA, M. D. G.; CORDOBA, J. J. LÓPEZ, M. C.; JORDANO, R. Implantacion del sistema ARICPC/APPCC em precocinados congelados. Alimentaria, n. 291, p. 39-46, abr. 1998.

7 EUSTACE, I.J. Control of bacterial contamination of meat during processing. Food Technology in Australia, v. 33, n. 1, p. 28-33, jan. 1981.

8 EVANGELISTA, J. Tecnologia de alimentos. 2. ed. Rio de Janeiro: Atheneu, 2000. 652 p.

9 FRANCO, B. D. G. de M.; LANDGRAF, M. Microbiologia dos alimentos. São Paulo: Atheneu, 1996.182 p.

10 FRAZIER, W. C.; WESTHOFF, D. C. Microbiologia de los alimentos. 4. ed. Zaragoza: Acribia, 1993. 681 p.

11 HAYES, P. R. Microbiologia e higiene de los alimentos. Zaragoza: Acribia, 1993. 369 p. 
12 ICMSF. International Commission on Microbiological Specifications for Foods. APPCC na qualidade e segurança microbiológica de alimentos. São Paulo: Varela, 1997. 377 p.

13 JAY, J. M. Microbiologia moderna de los alimentos. 3. ed. Zaragoza: Acribia, 1994. 804 p.

14 KVENBERG, J.; STOLFA, P.; STRINGFELLOW, D.; GARRETT, E. S. HACCP development and regulatory assessment in the United States of America. Food Control, n. 11, p. 387-401, 2000.

15 NACMCF. National Advisory Committee on Microbiological Criteria for Foods. Generic HACCP for raw beef. Food Microbiology, v. 10, p. 449-488, 1993.

16 OGAWA, M.; MAIA, E.L. Manual de pesca: ciência e tecnologia de pescado. São Paulo: Varela, 1999. 430 p.

17 PIERSON, M.; CORLETT JR, D. A. HACCP: principles and applications. New York: Chapman \& Hall, 1992. 212 p.

18 PRICE, J. F.; SCHWEIHERT, B. S. Ciencia de la carne y los productos carnicos. 2. ed. Zaragoza: Acribia, 1994. 581 p.

19 RIEDEL, G. Controle sanitário de alimentos. 2. ed. São Paulo: Atheneu, 1992. $320 \mathrm{p}$.

20 SENAI. Serviço Nacional de Aprendizagem Industrial. Elementos de apoio para o sistema APPCC. Brasília, 1999. 371 p. (Série Qualidade e Segurança Alimentar).

21 SILVA JR, E. A. Manual de controle higiênico-sanitário de alimentos. 2. ed. São Paulo: Varela, 1995. 385 p.

22 SIMONSEN, B.; BRYAN, F. L.; CHRISTIAN, J. H. B.; ROBERTS, T. A.; TOMPKIN, R. B.; SILLIKER, J. H. Prevention and control of foodborne salmonellosis through application of Hazard Analysis Critical Control Point (HACCP). International Journal of Food Microbiology, v. 4, p. 227, 1987.

23 SBCTA. Sociedade Brasileira de Ciência e Tecnologia de Alimentos. Manual de análise de perigos e pontos críticos de controle. 2. ed. São Paulo, 1995. 29 p. 